\title{
The unusual biology of marine file snakes with a perspective for the conservation of Acrochordus granulatus
}

\author{
Harvey B. Lillywhite
}

\begin{abstract}
Biodiversity and the function of tropical shallow-water marine environments are threatened by numerous anthropogenic factors, especially climate change, overharvesting of resources, and destruction of habitat. Marine snakes are important components of coastal shallow-water systems and should be considered as indicators of the health of coastal ecosystems such as mangroves. Acrochordid snakes (Acrochordidae: Acrochordus) represent a highly distinct evolutionary lineage with unusual adaptations to shallow water habitats and importance to biodiversity of tropical coastal regions. One of three congeneric species, Acrochordus granulatus (file snake), is an interesting and common inhabitant of coastal estuaries and mangroves in the Philippines. This paper reviews unusual attributes of $A$. granulatus and provides a perspective for its conservation in coastal habitats. Morphological, physiological, and behavioral characters of this snake are specialized for life in shallow-water marine environments such as mangroves. Unusual and specialized features confer abilities for prolonged submergence and include low metabolic rate, large capacity for oxygen storage, cutaneous gas exchange, nearly complete utilization of oxygen stores during aerobic submergence, intracardiac and cutaneous shunts for regulating blood flow, and reclusive behavior. Fresh water is required for water balance, and file snakes are dependent on rainfall in many habitats where they drink from freshwater lenses formed by precipitation on the surfaces of marine water. File snakes feed largely on fishes and are candidates as bio-indicators of the health of shallow-water coastal habitats. Attention should be given to threatening insults on coastal environments including climate change, habitat destruction, harvesting of resources, and other factors in need of research, monitoring, and plans for abatement. Importantly, conservation can be promoted by educating people about the docile behavior, unusual traits, and interesting ecology of A. granulatus.
\end{abstract}

Keywords: mangrove, shallow water, Acrochordidae, little file snake, conservation physiology, ecophysiology

\section{Introduction}

Biodiversity associated with tropical estuarine and shallow -water environments is threatened by numerous anthropogenic pressures including climate change, habitat destruction, overharvesting of marine resources, tourism, pollution, disease, agricultural runoff and other factors. Global warming and rise of sea levels are threatening mangroves and other nearshore habitats, which are important nurseries and biodiverse regions that have promoted diversification and evolutionary transitions between terrestrial and marine environments (Field 1995; Ward et al. 2016). Recent studies and perspectives based on the knowledge of ecology and natural history of shallow-water

Department of Biology, University of Florida, Gainesville, Florida USA

*Corresponding email: hblill@ufl.edu

Date Submitted: 29 June 2020

Date Accepted: 14 December 2020 marine ecosystems have promoted consideration of sea snakes as bio-indicators for the health of these systems (Reed et al. 2002; Ineich et al. 2007; Brischoux et al. 2009; Udyawer 2018; Rasmussen et al. 2020).

Sea snakes include about eight species of semiaquatic oviparous sea kraits (Laticauda spp.) and a little more than 65 species of entirely marine viviparous "true" sea snakes (Heatwole 1999, 2019; Sanders et al., 2008; Gherghel et al., 2016; Lee et al., 2016; Heatwole et al., 2017). The two lineages of sea snakes adapted independently to seawater and did not share a common marine ancestor. Marine or brackish-water snakes other than sea snakes include $\leq 40$ species representing the Asian families Homalopsidae and Acrochordidae, neotropical Dipsadidae, African Grayidae, and Colubridae (Lillywhite et al., 2017). The majority of these species are associated with the Indian and Pacific Oceans.

Snakes of the family Acrochordidae - known as file snakes, wart snakes, or elephant trunk snakes - are exceptional for their appearance, morphology, behavior, and specializations related to reclusive submergence in shallow marine, estuarine, 


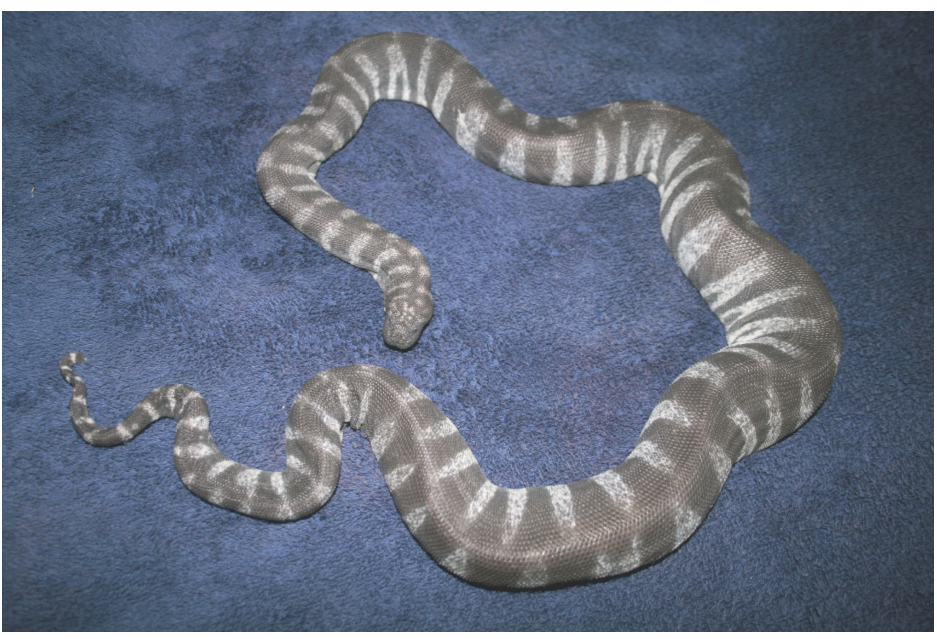

Figure 1. A Little file snake, Acrochordus granulatus.

and freshwater habitats. They are entirely aquatic and collectively distributed from India to the western edge of the Pacific. The acrochordid snakes include just three extant species belonging to a single genus. Acrochordus granulatus (Schneider, 1799) (Little file snake, hereafter referred to as file snake) was previously classified in a separate monotypic genus (Chersydrus) and is the smallest of the three acrochordid species (adults are $\sim 1 \mathrm{~m}$ total length) (Fig. 1). The other two species, A. javanicus Hornstedt, 1787 and A. arafurae McDowell, 1979, largely inhabit interior lakes, waterways, and other areas of permanent fresh water, whereas the distribution of A. granulatus is more coastal. All species may, at times, contact marine or brackish water, but only the latter species has numerous populations that are entirely marine. Many of the populations occur in coastal estuaries and mangroves.

Acrochordus granulatus has the most extensive distribution of the three species, ranging from west coastal India through tropical Asia to the Philippines, and south and east to New Guinea, northern Australia, and the Solomon Islands (Sanders et al., 2010). These snakes are sometimes found in the open sea (Voris and Glodek, 1980), and they enter numerous rivers at coastal locations (Lillywhite, 1991; Lillywhite and Ellis, 1994). Euryhalinity and dispersal along rivers explain their being found in various freshwater lakes, for examples, in Papua New Guinea, Australia, Singapore, Thailand, Cambodia and elsewhere (McDowell, 1979; Murphy et al., 1999; Ng, 2011). There is also a freshwater population that inhabits Lake Taal in the Philippines (Garcia et al., 2014).

The origin of modern file snakes corresponds quite closely with molecular estimates for the origins of viviparous sea snakes ( 16 Mya) which separated from the lineage to amphibious sea kraits much earlier (Sanders et al., 2010; Lee et al., 2016). There is only one described extinct species of Acrochordus, with fossils dating from 6.35-15 Mya (Head,
2005; Sanders et al., 2010). Despite superficial appearances, $A$. granulatus is more similar to A. arafurae, and these two species are sister to A. javanicus (Sanders et al., 2010). Interpretations of divergence times and fossil ecology suggest that the extant file snakes evolved from a freshwater ancestor and are a sister group to Colubroidea (Sanders et al., 2010). Hence, modern advanced snakes and the relatively primitive file snakes represent very different lineages. In the words of Sanders et al. (2010), species of Acrochordus "clearly represent highly distinct, long-separated evolutionary lineages, and as such comprise an important component of Indo-Australian biodiversity that should be included in regional conservation strategies."

This paper reviews the unusual biology of Acrochordus granulatus, which occurs abundantly in coastal regions of the Philippines (Fig. 2), and provides a perspective on its ecology and conservation. The information herein is based largely on laboratory research that was conducted in relation to numerous field trips to the Philippines. To provide an appropriate perspective for conservation of this species, the unusual physiological and morphological properties are discussed in relation to other relevant literature. My research activities with file snakes were hosted by Angel Alcala, and much of what follows would not have come to light without his generous and skilled assistance. I am indebted to Prof. Alcala for his professional guidance and friendship, for which I dedicate this paper to honor him.

\section{General appearance and ecomorphology}

File snakes are unusual in having very loose-fitting, "flabby" skin and convey the impression of being sluggish.

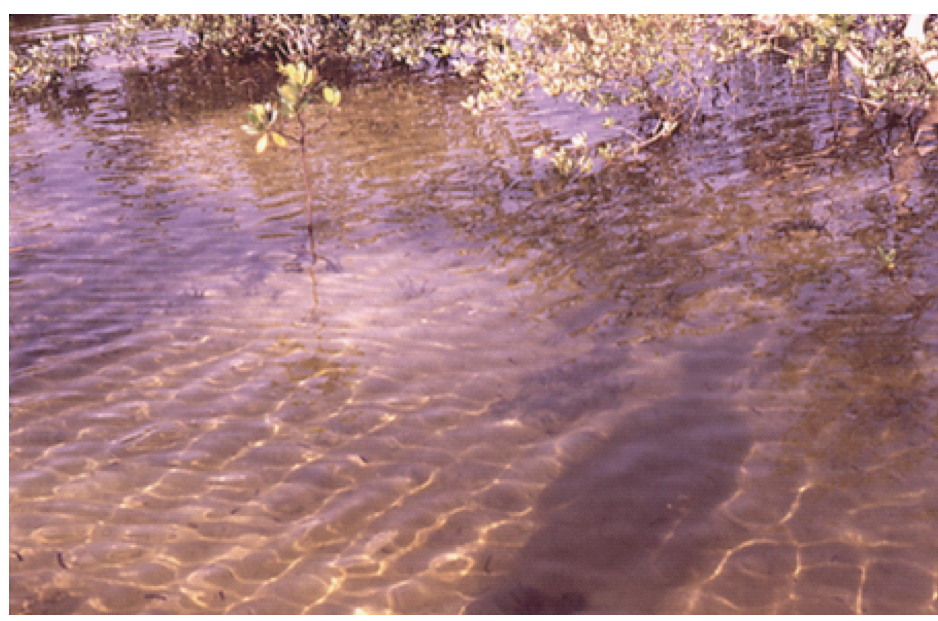

Figure 2. Shallow marine water of mangrove habitat where file snakes, Acrochordus granulatus, are common near the coastline of Negros, Philippines. 


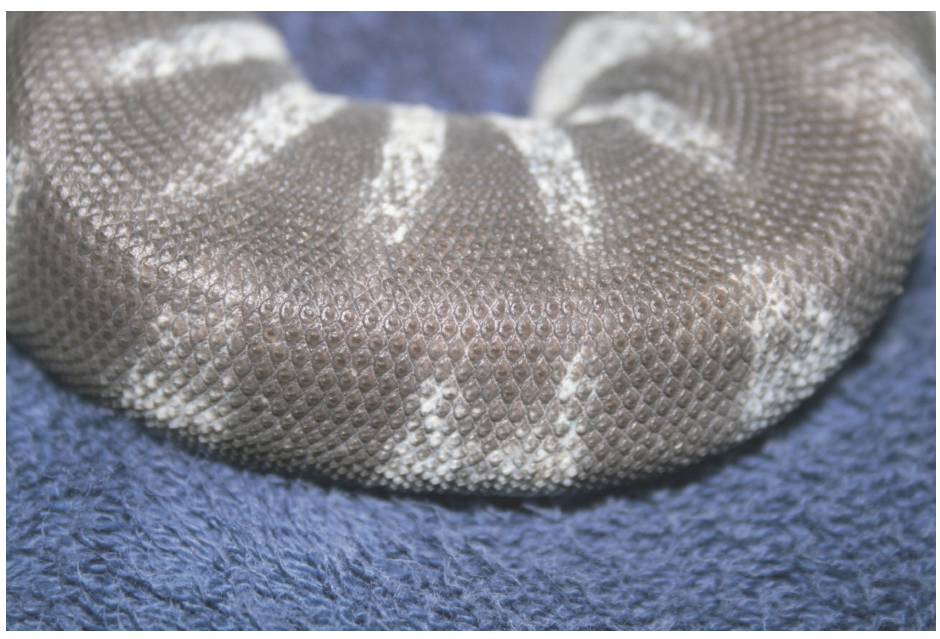

Figure 3. Dorsal and mid-dorsal skin of Acrochordus granulatus illustrating the spinose scales, each with a knoblike projection at its center. The central projections of each scale contain a sensory structure that is innervated and likely functions as a mechanoreceptor to sense changes in water pressure and movement near the snake.

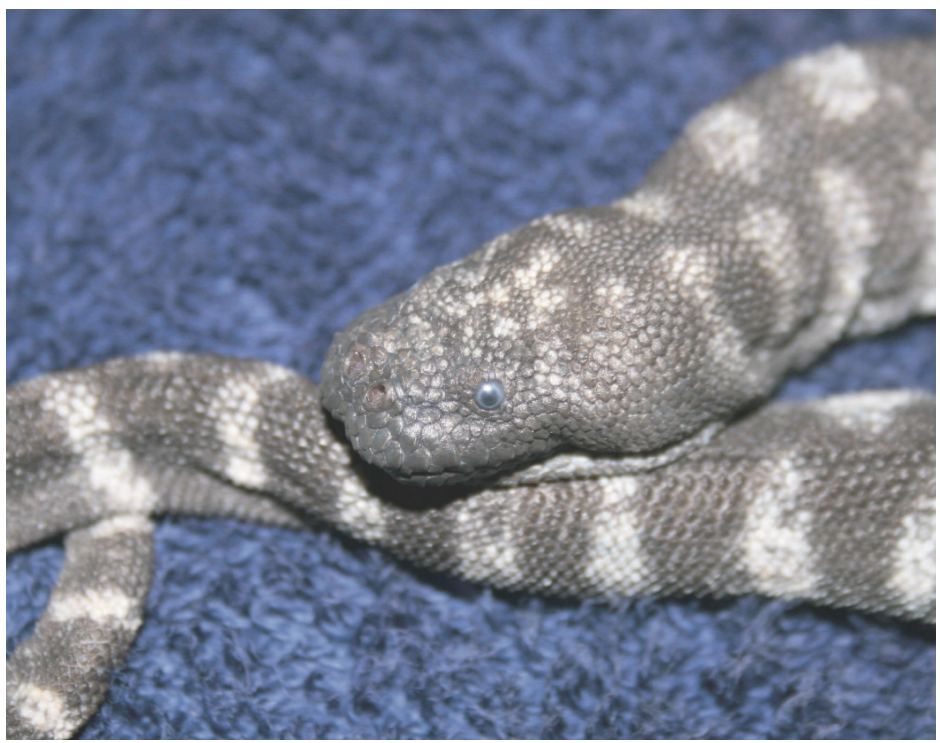

Figure 4. Head of a file snake, Acrochordus granulatus, illustrating the dorsal position of the eyes and valvular nostrils.

They are harmless and do not bite, sometimes being popular in the pet trade. Laboratory studies suggest that $A$. arafurae have low capacities for energy production and cannot sustain vigorous activity for more than a few minutes (Seymour et al., 1981). Although file snakes have the appearance of being sluggish, they are capable of very rapid movements when capturing fishes, which comprise their diet. Also, telemetry studies demonstrate that $A$. arafurae sometimes make extensive daily movements (Shine and Lambeck, 1985), and specimens of A. granulatus have been found considerable distances at sea as well as traveling river courses (McDowell, 1979; Voris and Glodek, 1980).
The flabby, loose-fitting skin of file snakes has diminutive, non-overlapping spinose scales (Figs. 1, 3). These scales exhibit prominent, innervated sensory structures having small hair-like sensillae that are densely distributed on the head and evidently are sensitive to water motion caused by fish (Povel and VanderKooij, 1997). The scalation and flexible properties of the skin enable file snakes to seize and hold struggling fish (Dowling, 1960). I have observed captive file snakes ensnare multiple small fish moving near the body while the snake was in the process of swallowing a first-caught fish. File snakes are able to quickly enwrap fish using body coils, but the action is not the same as the tightening constriction that is seen in other snakes such as boas and pythons (Lillywhite, 1996; Heatwole, 1999). The use of the body wraps to enclose fish is further aided by the lithe nature of the body musculature and lack of scutes or enlarged ventral scales. Flexibility of the body is further enhanced by relatively short vertebrae having a small, partially freed condyle (Johnson, 1955).

Related to aquatic habits, the eyes and nares of file snakes are directed upward (Fig. 4), and the location of the nares enables air breathing while virtually the entire body remains underwater (Fig. 5). The nares also contain fleshy tissues that, when erected, function as valves to close off and isolate the pulmonary system from ambient water when the snake is submerged (Fig. 6). The loose skin and supple musculature of the snake assist swimming by enabling pronounced lateral compression of the posterior aspect of the body. There are no enlarged ventral scutes characteristic of many other terrestrial snake taxa. The tail is laterally compressed to aid in swimming, but is not shaped in the form of a prominent paddle resembling the tail of sea snakes (Fig. 1). Although file snakes are capable swimmers, they are more often seen crawling over the muddy substrate among mangroves and appear to be more of a bottomdweller than active swimmer, at least in the shallow waters of mangroves. The density and pressure of surrounding water

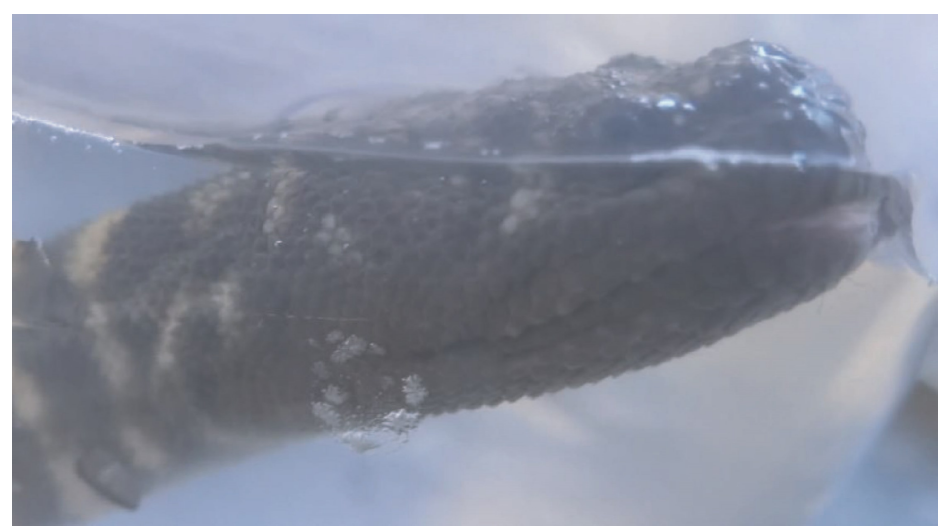

Figure 5. A file snake (Acrochordus granulatus) shown drinking from the surface while in a freshwater aquarium. 


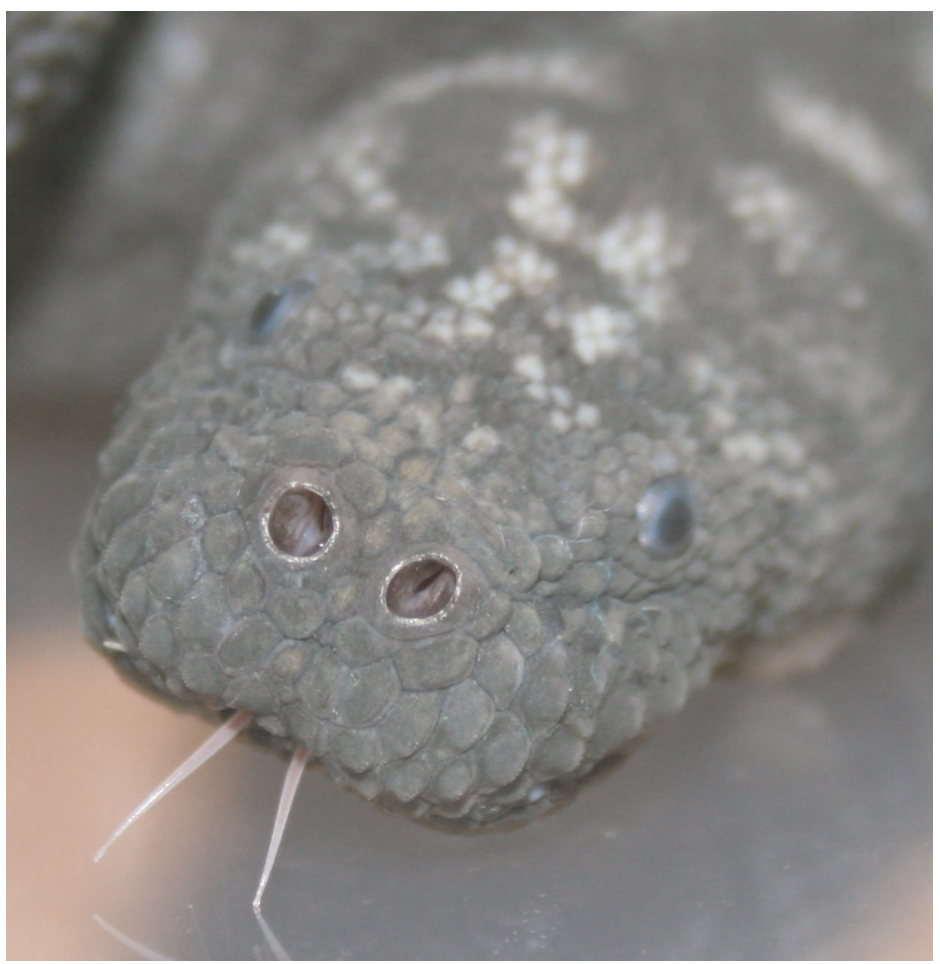

Figure 6. Head of a file snake (Acrochordus granulatus) illustrating the fleshy valves near the opening of the external nares. The valve structure within the nostril at the right is partially open, while the nostril at the left is more occluded by blood erection of the fleshy valve inside.

evidently are important to bottom-crawling, for the lateral body sags when snakes are in air, and file snakes do not move well on land. File snakes sometimes venture onto, or become stranded on, mud flats. Depending on the depth of water in mangrove habitats, swimming may or may not be involved when snakes elevate themselves in the water column for the purpose of airbreathing (Figs. 1, 5).

Specialized features of internal anatomy of file snakes include a central location of the heart, an elongated vascular lung with functional parenchyma throughout its length from neck to cloaca, a sublingual salt gland, and capacious veins associated with a relatively large blood volume (Feder, 1980; Lillywhite et al., 1988). Acrochordids also possess unusual features of cranial osteology (McDowell, 1979; Lee and Scanlon, 2002).

\section{Physiological adaptations for prolonged submergence}

File snakes exhibit unusual respiratory, cardiovascular, and metabolic character states that confer integrative adaptations for living in shallow marine environments (see Lillywhite, 1991; Lillywhite and Ellis, 1994). How these presumptive adaptations improve fitness is not precisely known, but clearly they enable prolonged submergence and seclusion of snakes to avoid biotic and physical stresses. Surfacing of file snakes exposes them to potential predation from sea eagles, large fishes, crocodiles, otters, and other predators including humans. Hiding in deeper water also avoids very high surface temperatures that can exceed $39{ }^{\circ} \mathrm{C}$ in Philippine mangroves during periods of hot weather (Lillywhite and Ellis, 1994). File snakes are largely nocturnal, so daytime surfacing is required only for bouts of air-breathing. During daylight, snakes typically remain submerged for long periods ranging from one to several hours while they rest on bottom substrate or in burrows or tangles of mangrove roots (Smith, 1914).

\section{Energy consumption, gas exchange and cardiorespiratory features}

Prolonged submergence of file snakes is attributable to low metabolic rate (or low energy consumption), comparatively large volume and oxygen capacity of blood, large lung oxygen stores, high-affinity and $\mathrm{pH}$-sensitive properties of blood, and cutaneous gas exchange (Lillywhite and Donald, 1989). The combined oxygen stores are efficiently utilized during prolonged submergence, when metabolic energy utilization is entirely aerobic. When snakes submerge following a bout of airbreathing, the blood is $\geq 90 \%$ saturated, and both blood and pulmonary oxygen stores are $80-90 \%$ depleted before snakes surface to renew the oxygen (Lillywhite and Smits, 1985). Ventilatory bouts while the nares of surfacing snakes contact air consist of several breaths spaced one to several minutes apart, during which the lung air is renewed, excess $\mathrm{CO}_{2}$ stores are eliminated, and the blood is re-saturated with oxygen (Seymour et al., 1981; Lillywhite and Donald, 1989; Lillywhite, 1991).

During a bout of lung ventilation, the heart rate increases 4 -7 fold and there is $\geq 10$-fold increase in pulmonary blood flow (Lillywhite and Donald, 1989). The increase in blood flow to the lung is attributable not only to the increase in heart rate but also to a net intracardiac shunting of blood, for systemic blood flow (in dorsal aorta) approaches zero while snakes are ventilating the lung. On the other hand, when the snake submerges again, systemic blood flow increases while the pulmonary blood flow diminishes to zero, except for periodic small pulses of blood flow that "meter out" the oxygen store of the lung. These changes in pulmonary blood flow are regulated by changes in the densely innervated lung vasculature, and the virtual complete pulmonary bypass of blood during diving represents the greatest functional lability of intracardiac shunts that has been demonstrated in any vertebrate (Lillywhite and Donald, 1989).

The likely utility of the extreme reduction of pulmonary blood flow during submergence is that it allows maintenance of 
a relatively low oxygen pressure in blood, which still delivers oxygen to tissues owing to the properties of hemoglobin (large Bohr shift) responding to acidification of the blood because of accumulating $\mathrm{CO}_{2}$ (Seymour et al., 1981; Lillywhite and Smits, 1985). The low oxygen pressure of blood favors uptake of oxygen from the lung as well as cutaneous uptake of oxygen from ambient water, and it minimizes losses of oxygen to water that can be hypoxic. In other words, the low blood $\mathrm{pH}$ attributable to $\mathrm{CO}_{2}$ accumulation during long periods of submergence in combination with the large Bohr shift of hemoglobin reduces its oxygen affinity and facilitates delivery of oxygen to tissues at very low levels of oxygen pressure that favor uptake of oxygen from the lung as well as the hypoxic waters of mangroves (Lillywhite and Ellis, 1994).

There is compelling but indirect evidence that passage of oxygen across the skin of file snakes is somehow regulated by changes in blood flow (Lillywhite and Ellis, 1994). Hence, if snakes are in well oxygenated water, it seems likely that cutaneous blood flow increases to favor uptake of oxygen and release of $\mathrm{CO}_{2}$. Alternatively, if the water surrounding a snake is hypoxic, it seems likely that cutaneous blood flow is minimized to reduce losses of blood oxygen to surrounding water. When snakes are in extremely hypoxic water, oxygen demands are met largely by increasing aerial uptake of oxygen via the lung (Pratt and Franklin, 2010). The oxygen content in the shallow waters of mangroves varies, and I have measured levels at or near zero within burrows where file snakes might seclude themselves (unpublished data; see also Lillywhite and Ellis, 1994). Hence, it is hypothesized that file snakes reduce cutaneous blood flow while in hypoxic or anoxic waters (e.g, inside burrows), but increase cutaneous blood flow when oxygen levels in surrounding water are higher, or when the $\mathrm{pH}$ attributable to accumulating $\mathrm{CO}_{2}$ decreases to a critical level (around 7.0). The latter phenomenon increases the losses of $\mathrm{CO}_{2}$ to water and thus prolongs the time of submergence even though the rate of depletion of oxygen stores might increase as well (Lillywhite and Ellis, 1994).

\section{Water balance and drinking}

In spite of the fact that $A$. granulatus has extrarenal salt glands, file snakes dehydrate in seawater and require drinking of fresh water to remain in water balance (Lillywhite, 1996; Lillywhite et al., 2014). Dunson (1979) reported that marine reptiles with salt glands can maintain sodium balance, but not water balance, when fasting in seawater. Hence, salt glands of file snakes likely are important for maintaining ion balance, and help to conserve water, but cannot alone keep snakes in water balance. File snakes drink from freshwater lenses that are formed during periods of heavy rainfall on the ocean, and this is the likely source of fresh water for snakes living in mangrove swamps that are away from estuaries. File snakes appear to be programed for this behavior inasmuch as they always drink from the surface when thirsty snakes are placed in any kind of container with fresh water (Fig. 5) (Lillywhite, 1996).

Drinking of fresh water by file snakes does not always appear to be associated with dehydration and might be necessary for removal of nitrogenous wastes that are excreted primarily in the form of ammonium (Lillywhite and Ellis, 1994). Ammonium elimination requires considerable amounts of water that cannot be supplied from the diet or metabolism. File snakes feed on fishes that incur obligatory production of nitrogenous waste. There is considerable evidence that snakes cannot maintain water balance by dependence on dietary water from food, and so drinking fresh water is necessary (Lillywhite et al., 2008; Lillywhite, 2017; Murphy and DeNardo, 2019).

\section{Challenges, opportunities, and conservation of file snakes}

The unusual features of acrochordid snakes suggest a number of implications for the risk to, as well as persistence of, populations living in shallow water marine habitats where anthropogenic assaults on these snakes and their habitats threaten survival of healthy populations. The "low-energy specializations" of these snakes, including sluggish and reclusive behavior, confer advantages of crypsis and ability to survive when food resources diminish. Seclusion in burrows and nocturnal behaviors of snakes render them difficult to find, and smaller and younger snakes, especially neonates, are rarely seen. Working with collectors in villages over several years, I have observed hundreds of snakes that were captured for scientific purposes, and rarely was a small snake included among the aggregate captures. Because of the low metabolic rates of file snakes, energy requirements are low (Heatwole and Seymour, 1975; Seymour et al., 1981; Lillywhite and Smits, 1985; Shine, 1986), including expenditure for activity that often reflects crawling slowly over mud substrata.

Growth rates and reproductive frequencies of file snakes appear to be low, and Shine (1986) suggested that A. arafurae might reproduce only once every $8-10$ years. Relatively little is known concerning the reproductive biology of the other species. In A. granulatus, litter size varies from 2-7 with a mean of about 5 individuals, and increases with increasing body size of the female (Voris and Glodek, 1980; Gorman et al., 1981; Wangkulangkul et al., 2005). Reproduction in file snakes is either aseasonal or seasonal depending on factors associated with geographic location (Voris and Glodek, 1980; Gorman et al., 1981; Wangkulangkul et al., 2005). Gestation time appears to be 5-8 months, which is uncharacteristically long for a reptile, 
and not all females reproduce annually (Gorman et al., 1981). Hence, like A. arafurae, A. granulatus appears to have low reproductive as well as growth rates (see also Sanders et al., 2010). Although the low energy requirements of file snakes can be advantageous with respect to variation or limitations of resources, the recovery of populations that might be reduced for various reasons is likely to be slow as well as at risk of extirpation.

As discussed elsewhere (Lillywhite and Ellis, 1994), the physiology of file snakes potentially limits seaward migration of populations that likely will remain tied to coastal or inland habitats. On the other hand, seawater infiltration of coastal zones might accommodate extension of ranges of the two freshwater species of file snake, assuming they can adapt to brackish or marine habitats (A. javanicus, and likely $A$. arafurae, will enter estuaries; Lillywhite and Ellis, 1994). File snakes living in mangrove habitats might experience extirpations in places where coastal development has eliminated features of landscape conducive to the inland migration of mangroves as sea levels rise. The continued existence of mangroves (with file snakes) will depend on rates of relative sea level rise, rates of mangrove die-off, maintenance of soil elevations within the intertidal habitat as sea level changes, and the nutrient regime of the habitat (Hutchings and Saenger, 1987; Field, 1995; McKee et al., 2007; Ward et al., 2016).

Information concerning the use of habitat and both finescale and long-term movements of file snakes is important to management of habitat and resources related to conservation of file snakes. Snakes are more active, and movements are more extensive at night than during the day (Lim, 1964; Shine and Lambeck, 1985; Lillywhite, 1991). Nocturnal movements of $A$. granulatus appear to be related to foraging, and I have observed these snakes patrolling shallow pools created at low tide where fishes can be concentrated. File snakes are also observed on saltwater mud flats and possibly move from pool to pool or to main watercourses during periods of low tide (Worrell, 1963; Lillywhite. 1991). In habitats with seasonal precipitation in northern Australia, A. arafurae sometimes move long distances across billabongs or from billabongs to grasslands inundated by seasonal flooding (Shine and Lambeck, 1985). Thus, the extent and nature of habitat can vary substantially in relation to season, precipitation, and tidal regimes. In terms of future research, however, there is need for better understanding file snakes with respect to connectivity of populations and metapopulation dynamics, capacity for dispersal, and the spatio-temporal uses of habitat.

File snakes bury themselves in mud if the particle size is not too coarse, and they hide among mangrove roots or inside holes and burrows that occur on substratum. Burrows that are

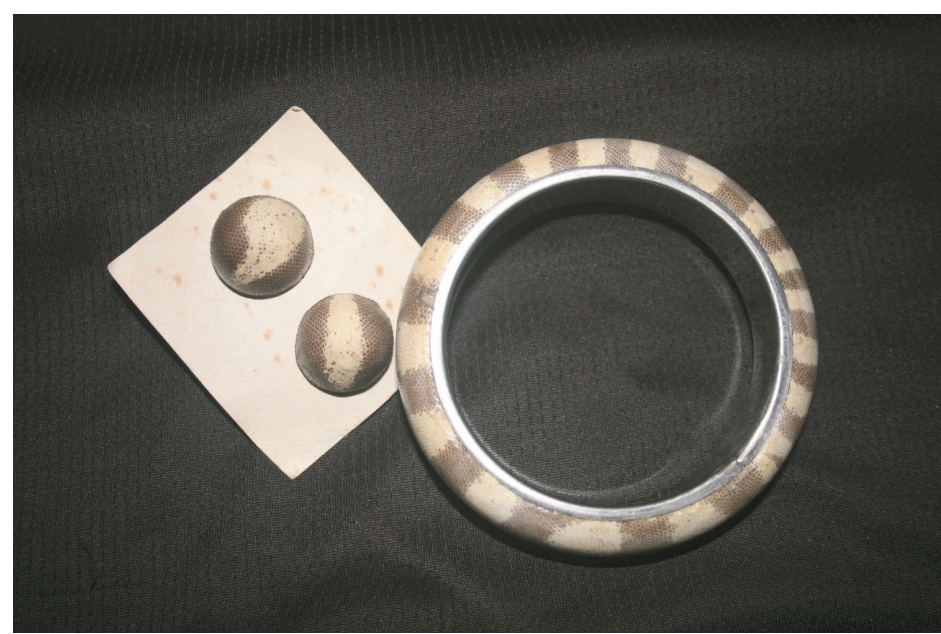

Figure 7. A bracelet and matching earrings decorated with skin from a file snake. Such items are sold in local markets in the Philippines.

occupied seem to be constructed by other animals (e.g., crustaceans) and not the snakes themselves. The two larger species of file snake tend to shelter in water beneath trees or other vegetation, and burrow under the roots of trees in river banks where they are sometimes found in large aggregations (Lim, 1964; Shine and Lambeck, 1985). Although A. granulatus has been captured in water at depths up to $20 \mathrm{~m}$ (Dunson and Dunson, 1973; Voris and Glodek, 1980), individuals of this species generally occupy water that is more shallow (Fig. 1) and subject to tidal fluctuation (Dunson and Minton, 1978; Lillywhite and Ellis, 1994). The reclusive behavior of file snakes, physiological adaptations for long periods of submergence between bouts of air-breathing, and sensory sensillae of the skin all enable these denizens of mangroves to hide, move, feed, and avoid predation in shallow and hypoxic waters often characterized by low visibility. Disturbance or destruction of these habitat features potentially exposes file snakes to increased pressures from predation and exploitive harvesting by humans. The extent to which file snakes are collected for commercial purposes is not known, but the skin of file snakes is used to make bracelets, earrings, and other items that are sold in local markets (Fig. 7).

File snakes feed almost exclusively on fish, with apparent specialization for gobiid and goby-like fishes, demersal forms often living in burrows or in crevices (Voris and Glodek, 1980; Garcia et al., 2014). Crustaceans are also sometimes eaten and are likely encountered with some regularity when snakes utilize their burrows (Cogger, 1975; McDowell, 1979). Although file snakes are predators on fishes, there is little information concerning the role of these snakes in the trophic structure of their habitat, their impact on fish populations, and whether there are dietary shifts with ontogeny or across habitats. Fishes that were eaten by file snakes and measured by Voris and Glodek 
(1980) were $\sim 10 \%$ of the snake's length in size. Isotopic studies suggest that file snakes are the top predators in the ecosystem of Lake Taal (Garcia et al., 2014). One could surmise, however, the impact of file snakes on fish populations is low because of their low demands for energy; on the other hand, densities of file snakes can be quite large so the aggregate impact could be substantial (e.g., 100 snakes/ha, representing a biomass $\geq 50 \mathrm{~kg} /$ ha, in A. arafurae; Shine, 1986). Thus, it might be hypothesized that the quantitative influence of file snakes on the trophic structure of their community likely varies from small to significant in different populations. Future research using stable isotopes and perhaps genetic markers could provide better understanding of trophic position, plasticity of diet, and possible shifts of dietary specializations across habitats. Related information on demography of this species also will be useful to develop strategies for conservation and understanding of changes in community structure and geographic range. We have no idea about variation of mortality rates, or how resilient populations of file snakes might be to ecological insult.

Currently an increasing database is expanding knowledge and awareness of marine snakes, and this has stimulated interest in efforts and proposals to protect them and to further understand their important roles in biotic communities of which they are a part (Udyawer et al., 2018). Acrochordus granulatus is a uniquely interesting species of snake, and its unusual suite of characters beg for researchers to investigate critical gaps of knowledge (e.g., energy investment in reproduction, resilience of populations) and implement management efforts to protect the habitats where this species resides via regulations to control coastal development and to set harvesting quotas. The establishment of marine protected areas could preserve important mangrove habitat, sustainable occupation of some areas by indigenous peoples, and preserve populations of file snakes at the same time and place. In agreement with the more general suggestion offered by Rasmussen et al (2020), $A$. granulatus could well serve as a bio-indicator for the health of mangrove habitats in which they reside. I also wish to emphasize the importance of a natural history perspective (Bartholomew, 1986; Tewksbury et al., 2014). File snakes are interesting in their own right, and there is tremendous value in their evolutionary innovations and scientific potential related to understanding their adaptations to shallow-water and mangrove environments. Perhaps the best means of promoting the conservation of this speciesss is the education of young people concerning the fascinating traits of this unusually docile and interesting species.

\section{Acknowledgements}

I am grateful to Martin Feder, Louis Guillette Jr., John Donald, Alan Smits, Kay Etheridge, Louis Somma, Tamir Ellis, C. Jabaly, L. Miller, Steven Lillywhite, and other persons who assisted with husbandry of file snakes and (or) research expeditions in the Philippines. I especially thank Prof. Angel Alcala for his generous and helpful assistance with logistics and accommodations as well as stimulating discussions during my visits. I am grateful to the students and staff at the Silliman Marine Laboratory and Silliman University, Dumaguete, Philippines for assistance with boat transportation, use of holding tanks, other logistical support, and stimulating discussions related to ecology of mangroves and marine snakes. Financial support for past work reported in cited publications was provided by the American Philosophical Society, National Institutes of Health (USA), and the University of Florida, Division of Sponsored Research.

\section{Literature Cited}

Bartholomew, G.A., 1986. The role of natural history in contemporary biology. BioScience, 36: 324-329.

Brischoux, F., X. Bonnet \& P. Legagneux, 2009. Are sea snakes pertinent bio-indicators for coral reefs? a comparison between species and sites. Marine Biology, 156: 1985-1992.

Cogger, H.G., 1975. Reptiles and Amphibians of Australia. A.H. \& A.W. Reed, London. 584 pp.

Dowling, H.G., 1960. The curious feeding habits of the Java wart snake. Animal Kingdom, 63:13-15.

Dunson, W.A., 1979. Control mechanisms in reptiles. In: Gilles, R. (ed), Mechanisms of osmoregulation in animals. Wiley Interscience, New York. Pp. 273-322.

Dunson, W.A. \& M.K. Dunson, 1973. Convergent evolution of sublingual salt glands in the marine filesnake and the true sea snakes. Journal of Comparative Physiology, 86: 193208.

Dunson, W.A. \& S.A. Minton, 1978. Distribution, and ecology of Philippine marine snakes (Reptilia, Serpentes). Journal of Herpetology, 12: 281-286.

Feder, M.E., 1980. Blood oxygen stores in the file snake, Acrochordus granulatus, and in other marine snakes. Physiological Zoology, 53: 394-401.

Field C.D., 1995. Impact of expected climate change on mangroves. In: Wong YS. \& N.F.Y. Tam, (eds), AsiaPacific Symposium on Mangrove Ecosystems. Developments in Hydrobiology, vol. 106. Springer, Dordrecht. https://doi.org/10.1007/978-94-011-0289-6_10.

Garcia, V.O.S., R.D.S. Papa, J.C.A. Briones, N. Mendoza, N. 
Okuda, \& A.C. Diesmos, 2014. Food habits and distribution of the Lake Taal sea snake (Hydrophis semperi Garman 1881) and the sympatric Little File Snake (Acrochordus granulatus Schneider 1799) in Lake Taal, Philippines. Asian Herpetological Research 5: 255-262.

Gherghel, I, M. Papeş, F. Brischoux, T. Sahlean, \& A. Strugariu, 2016. A revision of the distribution of sea kraits (Reptilia, Laticauda) with an updated occurrence dataset for ecological and conservation research. ZooKeys 569: 135-148.

Gorman, G.C., P. Licht \& F. McCollum, 1981. Annual reproductive patterns in three species of marine snakes from the central Philippines. Journal of Herpetology 15: $335-354$.

Head, J.J., 2005. Snakes of the Siwalik Group (Miocene of Pakistan): Systematics and relationship to environmental change. Palaeontologia Electronica 8.1, 16A: 1-33.

Heatwole, H., 1999. Sea Snakes. University of New South Wales Press, Sydney. 148 pp.

Heatwole, H., 2019. Isolation, dispersal, and changing sea levels. How sea kraits spread to far-flung islands. In: Lillywhite, H. \& M. Martins, (eds), Islands and Snakes. Isolation and Adaptive Evolution. Oxford University Press, New York. Pp. 45-71.

Heatwole, H., A. Grech, \& H. Marsh, 2017. Paleoclimatology, paleogeography, and the evolution and distribution of sea kraits (Serpentes; Elapidae; Laticauda). Herpetological Monographs 31: 1-17.

Heatwole, H. \& R. Seymour, 1975. Pulmonary and cutaneous oxygen uptake in sea snakes and a file snake. Comparative Biochemistry and Physiology, 51: 399-405.

Hutchings, P, \& P. Saenger, 1987. Ecology of Mangroves. University of Queensland Press, St. Lucia. 388 pp.

Ineich, I., X. Bonnet, F. Brischoux, M. Kulbicki, B. Seret \& R. Shine, 2007. Anguilliform fishes and sea kraits: Neglected predators in coral-reef ecosystems. Marine Biology, 151: 793-802.

Johnson, R.G., 1955. The adaptive and phylogenetic significance of vertebral form in snakes. Evolution, 9: 367388.

Lee, M.S.Y., K.L. Sanders, B. King \& A. Palci, 2016. Diversification rates and phenotypic evolution in venomous snakes (Elapidae). Royal Society Open Science 3: 150277. http://dx.doi.org/10.1098/rsos.150277

Lee, M.S.Y. \& J.D. Scanlon, 2002. Snake phylogeny based on osteology, soft anatomy and ecology. Biological Reviews 77: 333-401.

Lillywhite, H.B., 1991. The biology and conservation of acrochordid snakes. Hamadryad, 16: 1-9.
Lillywhite, H.B., 1996. Husbandry of the little file snake, Acrochordus granulatus. Zoo Biology, 15: 315-327.

Lillywhite H.B., 2017. Feeding begets drinking: insights from intermittent feeding in snakes. Journal of Experimental Biology, 220: 3565-3570.

Lillywhite, H.B., L.S. Babonis, C.M. Sheehy III, \& M.-C. Tu, 2008. Sea snakes (Laticauda spp.) require fresh drinking water: Implication for the distribution and persistence of populations. Physiological and Biochemical Zoology, 81: 785-96.

Lillywhite, H.B. \& J.A. Donald, 1989. Pulmonary blood flow regulation in an aquatic snake. Science, 245: 293-295.

Lillywhite, H.B. \& T.M. Ellis, 1994. Ecophysiological aspects of the coastal-estuarine distribution of acrochordid snakes. Estuaries, 17: 53-61.

Lillywhite, H.B., H. Heatwole, \& C.M. Sheehy III, 2014. Dehydration and Drinking Behavior of the Marine File Snake Acrochordus granulatus. Physiological and Biochemical Zoology, 87: 46-55.

Lillywhite, H.B., C.M. Sheehy III, H. Heatwole, F. Brischoux, \& D.W. Steadman, 2017. Why are there no sea snakes in the Atlantic? BioScience, 68: 15-24.

Lillywhite, H.B. \& A.W. Smits, 1985. Diving adaptations in the aquatic file snake, Acrochordus granulatus. Physiologist, 28: 283.

Lillywhite, H.B., A.W. Smits, \& M.E. Feder, 1988. Body fluid volumes in the aquatic snake, Acrochordus granulatus. Journal of Herpetology, 22: 434-438.

Lim, B.L., 1964. Notes on the elephant's trunk snake and the puff-faced water snake in Kuala Lumpur. Malayan Nature Journal, 18: 179-183.

McDowell, S.B., 1979. A Catalogue of the Snakes of New Guinea and the Solomons, with special reference to those in the Bernice P. Bishop Museum. Part III. Boinae and Acrochordoidea (Reptilia, Serpentes). Journal of Herpetology, 13: 1-92.

McKee, K.L., D.R. Cahoon, \& I.C. Feller, 2007. Caribbean mangroves adjust to rising sea level through biotic controls on change in soil elevation. Global Ecology and Biogeography, 16: 545-556.

Murphy J.C., H.K. Voris, D.R. Karns, T. Chan-ard, \& K. Suvunrat, 1999. The ecology of the water snakes of Ban Tha Hin, Songkhla Province, Thailand. Natural History Bulletin of the Siam Society, 47: 129-147.

Murphy M.S. \& D.F. DeNardo, 2019. Rattlesnakes must drink: Meal consumption does not improve hydration state. Physiological and Biochemical Zoology, 92: 381-385.

Ng, T.H., 2011. A record of the banded file snake, Acrochordus granulatus (Reptilia: Squamata: Acrochordidae) in a 
freshwater habitat in Singapore. Nature in Singapore, 4: 91 -93 .

Povel, D. \& J. VanDerKooij, 1997. Scale sensillae of the file snake (Serpentes: Acrochordidae) and some other aquatic and burrowing snakes, Netherlands Journal of Zoology, 47: 443-456.

Pratt, K.L. \& C.E. Franklin, 2010. Temperature independence of aquatic oxygen uptake in an air-breathing ectotherm and the implications for dive duration. Comparative Biochemistry and Physiology, Part A, 156: 42-45

Rasmussen, A.R, Hay-Schmidt, A., Boneka, F., Allentoft, M.E., Sanders, K.L., \& J. Elmberg, 2020. Viviparous Sea Snakes can be used as Bio-Indicators for Diverse Marine Environments. Philippine Journal of Systematic Biology, 14(2).

Reed, R.N., R. Shine \& S. Shetty, 2002. Sea kraits (Squamata: Laticauda spp.) as a useful bioassay for assessing local diversity of eels (Muraenidae, Congridae) in the Western Pacific Ocean. Copeia, 2002: 1098-1101.

Sanders, K.L., M.S.Y. Lee, R. Leys, R. Foster \& J.S. Keogh, 2008. Molecular phylogeny and divergence dates for Australasian elapids and sea snakes (hydrophiinae): evidence from seven genes for rapid evolutionary radiations. Journal of Evolutionary Biology, 21: 682-695.

Sanders, K.L., Mumpuni, A. Hamidy, J.J. Head, \& D.J. Gower, 2010. Phylogeny and divergence times of filesnakes (Acrochordus): Inferences from morphology, fossils and three molecular loci. Molecular Phylogenetics and Evolution, 56: 857-867.

Seymour, R.S., G.P. Dobson, \& J. Baldwin, 1981. Respiratory and cardiovascular physiology of the aquatic snake, Acrochordus arafurae. Journal of Comparative Physiology, 144: 215-227.

Shine, R. \& R. Lambeck, 1985. A radiotelemetric study of movements, thermoregulation, and habitat utilization of Arafura filesnakes (Serpetentes: Acrochordidae). Herpetologica, 41: 351-361.

Shine, R., 1986. Ecology of a low-energy specialist: Food habits and reproductive biology of the arafura filesnake (Acrochordidae). Copeia, 1986:424-437.

Smith, M., 1914. The snakes of Bangkok. Journal of Natural History Society of Siam, 1: 5-18.

Tewksbury, J.J., J.G.T. Anderson, J.D. Bakker, T.J. Billo, P.W. Dunwiddie, M.J. Groom, S.E. Hampton, S.G. Herman, D.J. Levey, N.J. Machnicki, C.Martínez del Rio, M.E. Power, K. Rowell, A.K. Salomon, L Stacey, S.C. Troombulak, \& T.A. Wheeler, 2014. Natural history's place in science and dociety. BioScience, 64: 300-310.

Udyawer, V., P. Barnes, X. Bonnet, F. Brischoux, J.M. Crowe-
Riddell, B. D'Anastasi, B.G. Fry, A. Gillett, C. Goiran, M.L. Guinea, H. Heatwole, M.R. Heupel, M. Hourston, M. Kangas, A. Kendrick, I. Koefoed, H.B. Lillywhite, A.S. Lobo, V. Lukoschek, R. McAuley, C. Nitschke, A.R. Rasmussen, K.L. Sanders, C. Sheehy III, R. Shine, R. Somaweera, S.S. Sweet, \& H.K. Voris, 2018. Future directions in the research and management of marine snakes. Frontiers in Marine Science, 5: article 399. Pp. 116.

Voris, H.K. \& G.S. Glodek, 1980. Habitat, diet and reproduction of the file snake, Acrochordus granulatus, in the Straits of Malacca. Journal of Herpetology, 14: 105-108.

Wangkulangkul, S., K. Thirakhupta, \& H.K. Voris, 2005. Sexual Size Dimorphism and Reproductive Cycle of the Little File Snake Acrochordus granulatus in Phangnga Bay, Thailand. Science Asia 31: 257-263.

Ward. R.D., D.A. Friess, R.H. Day, \& R.A. MacKenzie, 2016. Impacts of climate change on mangrove ecosystems: a region by region overview. Ecosystem Health and Sustainability, 2: e01211. https://doi.org/10.1002/ehs2.1211 Worrell, E., 1963. Reptiles of Australia. Angus and Robertson, Sydney. 